\title{
Readiness for oral feeding and oral motor function in preterm infants
}

\section{Prontidão para início da alimentação oral e função motora oral de recém-nascidos pré-termo}

Raquel Coube de Carvalho Yamamoto(1) Leila Sauer Prade ${ }^{(1)}$ Geovana de Paula Bolzan(2) Angela Regina Maciel Weinmann ${ }^{(3)}$ Márcia Keske-Soares ${ }^{(4)}$

\footnotetext{
(1) Universidade Federal de Santa Maria UFSM - Santa Maria (RS), Brasil.

(2) Hospital Universitário de Santa Maria, Universidade Federal de Santa Maria UFSM - Santa Maria (RS), Brasil.

(3) Departamento de Pediatria e Puericultura, Universidade Federal de Santa Maria - UFSM - Santa Maria (RS), Brasil.

(4) Departamento de Fonoaudiologia Universidade Federal de Santa Maria UFSM - Santa Maria (RS), Brasil.

Research developed in the Programa de Pós-Graduação em Distúrbios da Comunicação Humana, Universidade Federal de Santa Maria - UFSM - Santa Maria (RS), Brasil.
}

Conflict of interest: non-existent

Received on: October 18, 2016 Accepted on: June 12, 2017

Mailing adress:

Raquel Coube de Carvalho Yamamoto

Rua Rubem Martins Berta, 103

Camobi, Santa Maria, RS, Brasil

CEP: $97105-350$

E-mail: raquelcoube@yahoo.com.br

\section{ABSTRACT}

Objective: this study aimed at investigating the Schedule Oral Motor Assessment (SOMA) tool to be used with preterm infants and to compare its results with the Preterm Oral Feeding Readiness Assessment Scale (POFRAS) to start oral feeding.

Methods: a cross-sectional and quantitative study, consisting in a sample of 45 healthy and clinically stable preterm infants, assessed at their first oral feeding with two tools: the Schedule Oral Motor Assessment and Preterm Oral Feeding Readiness Assessment Scale. Stata 10.0 software was used for data analysis.

Results: 10 preterm infants with readiness for oral feeding showed normal oral motor function, and 16 , presented with oral motor dysfunction, did not show readiness for feeding $(p<0.05)$. The time of transition for full oral feeding was $13.5( \pm 8.1)$ days for preterm infants with better results in both assessment tools, and $17.7( \pm 10.9)$ days for those who did not show readiness for oral feeding and had oral motor dysfunction to initiate oral feeding, resulting in a given clinical relevance, even showing no significance (p> 0.05).

Conclusion: these results suggest that the Schedule Oral Motor Assessment can be an adjunctive method for evaluation of the oral motor function at the first oral feeding in preterm infants.

Keywords: Infant, Premature; Sucking Behavior; Aptitude; Feeding Behavior

\section{RESUMO}

Objetivo: investigar o Schedule Oral Motor Assessment (SOMA) para utilização com recém-nascidos pré-termo, e comparar seus resultados com o Preterm Oral Feeding Readiness Scale (POFRAS) na liberação da alimentação por via oral.

Métodos: trabalho de caráter transversal e quantitativo. Estudo composto por uma amostra de 45 recém-nascidos pré-termo, saudáveis e clinicamente estáveis, avaliados no momento da liberação da alimentação por via oral. Neste momento foi realizada a avaliação do POFRAS e do SOMA. Para a análise dos dados foi utilizado o software Stata 10.0.

Resultados: todos 10 recém-nascidos pré-termo que apresentaram prontidão para alimentação por via oral tinham função motora oral normal, e, os 16 que apresentaram disfunção motora oral, esses não apresentavam prontidão para a mamada $(p<0,05)$. 0 tempo de transição de alimentação por via oral foi de 13,5 $( \pm 8,1)$ dias nos recém-nascidos pré-termo, com melhores resultados nas duas avaliações, e de $17,7( \pm 10,9)$ dias aos que não apresentaram prontidão para a alimentação oral e tiveram disfunção motora oral no momento da liberação da via oral, resultando em um dado com relevância clínica mesmo não apresentando significância $(p>0,05)$.

Conclusão: estes resultados sugerem que o SOMA pode ser um método complementar para avaliação da função oral-motora no momento da liberação da via oral de recém-nascido pré-termo.

Descritores: Prematuro; Comportamento de Sucção; Aptidão; Comportamento Alimentar 


\section{INTRODUCTION}

The preterm newborn infant presents a critical health situation during the neonatal period, and might present several intercurrences. Such intercurrences favour a prolonged permanence in the Neonatal Intensive Care Unit (NICU), thus inhibiting the success of feeding via the oral route in the appropriate moment ${ }^{1,2}$. In order to benefit the nutritional necessities of the preterm newborn infant, feeding is provided, initially, trough feeding tubes, yet after being released to begin feeding through the oral route, the prolonged use of tubes can interfere with the baby's oral skills ${ }^{3}$.

Factors such as the preterm newborns' corrected gestational age ${ }^{4}$, clinical condition, behavioural state ${ }^{5}$, weight, as well as organs and systems adequacy ${ }^{6}$ influence on adequate skill in the beginning of feeding via the oral route. Even with these positive factors favouring a satisfactory result, as regards preterm born infants, it becomes necessary to conduct an assessment to ascertain the real condition of the infant for receiving oral feeding in an efficient, safe and riskless way.

The adequate coordination among the functions of sucking, deglutition and breathing is essential for the success of oral feeding. The corrected gestational age of 34 weeks is expected to be the moment when the preterm newborn begins to acquire such functions in a coordinated form ${ }^{4,7}$. However, even though the criterion of gestational age is argued for the release to initiate the oral route ${ }^{3}$, this isolated factor alone should not be determinant for the beginning of feeding via the oral route, since literature indicates coordination among the functions in preterm newborns with 32 weeks of corrected gestational age ${ }^{8}$.

The Preterm Oral Feeding Readiness Scale (POFRAS) $^{9,10}$, an instrument for assessing the preterm infant's readiness to begin the supply of feeding through oral route, constitutes a proposal drafted and validated for the demand of prematures in Brazil, created with the aim of assisting professionals working directly with the feeding aspects to predict the beginning of oral feeding without risk for the preterm born infants. It consists of an ample evaluation, approaching several factors such as maturity, state of consciousness, oral motor skills, and also nonnutritive sucking characteristics ${ }^{10}$.

The Schedule for Oral Motor Assessment (SOMA) ${ }^{11}$ is an instrument for objective evaluation of oral motor function, developed to check the oral motor skill in infants with ages between 8 and 24 months. Its aim is to detect, in a specific level of functioning, the skill areas presenting any deficit which can contribute for feeding difficulty. This assessment can be applied without special equipment, but it must be realized by a trained observer, in order to evaluate the oral motor function with a variety of feeding textures. In the case of newborns, only the category milk bottle is used.

Both assessments, even being conducted in independent moments of sucking - POFRAS being employed during the nonnutritive suction and SOMA in the nutritive one - may complement and justify the results, thus corroborating to the completion of the diagnosis and the necessities of the preterm born infant. An appropriate diagnosis of the real oral motor necessities of the preterm newborn assists in the elaboration of a plan of oral motor sensorial stimulation to be developed in order to foster the oro- or nasogastric tube weaning as earliest as possible.

The objective of this study was to inquire about the use of SOMA with preterm newborns, as well as to compare the results of SOMA with those of POFRAS in the release for the beginning of feeding via the oral route.

\section{METHODS}

This work has a cross sectional and quantitative design. It was approved by the Ethics Committee in Research of the Universidade Federal de Santa Maria under the number 11155312.7.0000.5346. All persons legally in charge of the preterm newborn participants of this research signed the Free Informed Consent Form.

In this study took part 45 preterm born infants admitted to the NICU of the University Hospital of the originating institution during the period comprised between November 2013 and February 2015. The inclusion criteria consisted in the preterm born babies having gestational age below 37 weeks at birth and being clinically stable. The preterm babies presenting neurological changes, genetic syndromes, head or neck malformations, neonatal asphyxia (5-Minute Apgar Score of $\leq 5$ ), bilirubin encephalopathy, intraventricular hemorrhage degrees III and IV and bronchopulmonary dysplasia were excluded.

The data concerning each preterm born infant as to gestational age and weight at birth, corrected gestational age, weight and days of life in the release of the oral route, and the transition time from the beginning of the oral route until the preterm infant being able to drink the whole volume prescribed for a 24-hour period were collected from the medical records available at the Neonatal Intensive Care Unit. After release 
for introduction of feeding through oral route by the medical team in charge, which follows the criterion of corrected gestational age of 34 weeks, weight above $1500 \mathrm{~g}$ and being clinically stable, the preterm born baby was put into lateral decubitus position and evaluated. The POFRAS and SOMA assessments were conducted by phonoaudiologists available in the NICU, who were experienced in the area of neonatal orofacial motricity by means of the respective instruments.

The POFRAS tool is composed of 18 assessment items, distributed among five categories, each item scoring from zero to two, and the final scoring varying from zero to 36 according to the characteristics presented by the preterm newborn. As for the result, presence of readiness to begin oral route feeding was considered for the preterm born babies with score $\geq$ 30 , whereas absence of readiness was considered for those with score $<30^{9,10}$.

In order for the factor fatigue not to interfere in the first breast feeding performance, the babies rested for fifteen minutes after the POFRAS application. After this period, the preterm born infant was positioned on a supine position, with the head aligned with the body, keeping a 45 degree elevation to start the offering of the first breast feeding via the oral route, and departing from this point the assessment tool SOMA was applied. The feeding bottle used for assessment was from Dr. Brown brand with a nipple and a hole for the outward flow of milk.

It is important to report that all preterm born infants were fed exclusively by means of orogastrical tube, did not receive any previous oral motor sensory stimulation, and were clinically stable for phonoaudiological evaluation. In the end of the phonoaudiological evaluation, to the preterm newborn presenting favourable clinical conditions, performance and skill to start oral feeding, the maternal breast was recommended to carry on the feeding transition in order for the breastfeeding to begin safely and riskless.

In the SOMA assessment, which was applied only with the category milk in the nursing bottle, issues observed were the reaction of anticipated opening of mouth, whether any liquid was sucked, the acceptance of the bottle starting sucking until two seconds, positioning of the lips on the bottle nipple during sucking and deglutition, vertical jaw movement, and whether it presented gentle sequenced rhythm. The liquid offered was that prescribed by the medical team in charge of the preterm infant. It could be the breast milk and, in case it was not possible, a milky formula with appropriate composition for this population was utilized. The scoring presents two alternatives (yes and no) in each of the nine items proposed. To present a result below five scores means that the oral motor function is normal, whereas getting scores equal or above five suggests the presence of oral motor dysfunction.

The assessments, both POFRAS and SOMA, were suspended upon any risk factor presented by the preterm born child, such as crying, cough, hiccups, choking, heart rate and breathing alteration above or below the base parameter prescribed for preterm born children, as well as presence of drop of oxygen saturation observed during the handling and supply of the nursing bottle.

The time of feeding transition was measured in days, accounting the days from the release of the oral route up to the date when the preterm born infant swallows the whole volume prescribed in all breast feeding hours during the period of one day. The preterm infants who presented oral motor dysfunction or any clinical discomfort such as drop of saturation, change of breathing and heart rate during the phonoaudiologic evaluation in the release of the oral route were observed, after the evaluation, by a phonoaudiologist with oral motor sensory stimulation and resistance training for feeding via the oral route.

For data analysis, the software Stata 10.0 was employed. To obtain mean and standard deviation, the $t$ Student Test was used, and for comparison among the categorical variables, the $\chi^{2}$ Test was utilized. The level of significance considered was $5 \%(p<0,05)$.

\section{RESULTS}

The general characteristic of the sample was composed of $47 \%$ of preterm born male babies. At birth, all newborns presented mean and standard deviation for the gestational age of 33,4 weeks $( \pm 1,9)$ and for the weight of $1751,3( \pm 495,6)$. In the release of the oral route, the mean of corrected gestational age, weight and days of life was $34,9( \pm 1,1)$ weeks, 1888 $( \pm 354,6)$ grams and $11,5( \pm 11,4)$ days respectively. This sample presented a mean of $15,6( \pm 9,7)$ transition days to reach a full feeding via the oral route. These data are shown in Table 1. 
Table 1. General characteristics of the 45 preterm newborns at birth, in the release of the oral route and in the feeding transition time

\begin{tabular}{lc}
\hline Variables & \\
\hline Gender (\%) & 47 \\
$\quad$ Male & 53 \\
Female & $33,4( \pm 1,9)$ \\
\hline At birth* & $1751,3( \pm 495,6)$ \\
$\quad$ Gestational age (weeks) & $34,9( \pm 1,1)$ \\
Weight (g) & $1888( \pm 354,6)$ \\
\hline Beginning of the oral route* & $11,5( \pm 11,4)$ \\
$\quad$ Corrected gestational age (weeks) & $15,6( \pm 9,7)$ \\
Weight (g) & \\
Days of life & \\
\hline Feeding transition days*
\end{tabular}

* Values expressed in mean and standard deviation, analysis using t-Student test

In Table 2 the outcomes of the POFRAS assessment are displayed, including 10 preterm newborn babies who presented readiness for the beginning of feeding by oral route (score $\geq 30$ ) and 35 babies who did not present such a readiness (score $<30$ ), as well as are displayed the outcomes of the SOMA assessment, with a sample of 29 preterm newborns presenting adequate oral motor function (score $<5$ ) and 16 presenting oral motor dysfunction (score $\geq 5$ ) in the first breast feeding via the oral route. It can be noticed that all the 10 preterm newborn infants presenting readiness for oral feeding had normal oral motor function, whereas all the 16 preterm newborn babies presenting oral motor dysfunction also did not present readiness for breast feeding. These outcomes presented a significance of $p<0,05$.

Table 2. Sample result in the Preterm Oral Feeding Readiness Scale and Schedule for Oral Motor Assessment evaluations

\begin{tabular}{|c|c|c|c|}
\hline \multicolumn{4}{|l|}{ Variables } \\
\hline & \multicolumn{2}{|c|}{ SOMA } & \multirow[b]{2}{*}{ Value of $p$} \\
\hline & $\begin{array}{c}\text { Score }<5 \\
(n=29)\end{array}$ & $\begin{array}{c}\text { Score } \geq 5 \\
(n=16)\end{array}$ & \\
\hline \multicolumn{4}{|l|}{ POFRAS } \\
\hline Score $\geq 30(n=10)$ & $10(22 \%)$ & 0 & \\
\hline Score $<30(n=35)$ & $19(42 \%)$ & $(35 \%)$ & 0.008 \\
\hline
\end{tabular}

*Values expressed in number of subjects and its respective percentage within the sample, analysis using $\square^{2}$ test, $p<0,05$

Legend: POFRAS - Preterm Oral Feeding Readiness Scale; SOMA - Schedule for Oral Motor Assessment

By separating the sample only with the preterm newborns who presented concordance between the outcomes of the POFRAS and SOMA evaluations (10 subjects with readiness to start feeding through the oral route (POFRAS $\geq 30$ ) and normal oral motor function (SOMA $<5)$, and 16 subjects without readiness (POFRAS $<30$ ) and oral motor dysfunction $(S O M A \geq 5))$ and analyzing the relationship of these outcomes with the time of transition of feeding via the oral route, average results (DP) were obtained of 13,5 $( \pm 8,1)$ transition days to the preterm newborns with readiness for oral feeding and adequate oral motor function, and 17,7 $( \pm 10,9)$ days to those who did not present readiness for oral feeding and manifested oral motor dysfunction in the moment of the release of the oral route. These results did not display significance, showing value $p>0,05$ (Table 3 ). 
Table 3. Feeding transition time of preterm newborns with readiness for breast feeding (POFRAS $\geq 30$ ) and normal motor function $(\mathrm{SOMA}<5)$, and without readiness for breast feeding (POFRAS $<30$ ) and with oral motor dysfunction $(\mathrm{SOMA} \geq 5)$

\begin{tabular}{lccc}
\hline Variables & & & \\
\hline POFRAS & Score $\geq \mathbf{3 0}$ & Score $<\mathbf{3 0}$ & Value of $\mathbf{p}$ \\
SOMA & Score $<\mathbf{5}$ & Score $\mathbf{~ 5}$ & \\
\hline $\mathrm{N}$ & 10 & 16 & \\
Feeding transition days* & $13,5( \pm 8,1)$ & $17,7( \pm 10,9)$ & 0.1495 \\
\hline
\end{tabular}

* Values expressed in mean and standard deviation, analysis using t-Student test

Legend: POFRAS - Preterm Oral Feeding Readiness Scale; SOMA - Schedule for Oral Motor Assessment

\section{DISCUSSION}

Corrected gestational age, weight and clinical stability are the parameters most frequently used by the medical team in order for the preterm newborn to start feeding via the oral route. However, not always these factors are indicative of the necessary maturity for that population to present adequate performance during breast feeding. Some studies agree that clinical stability might be intimately connected with the adequate coordination among the functions of sucking, deglutition and breathing in the feeding efficiency ${ }^{3,12}$.

The results obtained in the assessment of the release of the oral route with average of corrected gestational age of $34,9( \pm 1,1)$ weeks and weight of $1888( \pm 354,6)$ grams concord with the medical criteria taken into account by the NICU in charge of this population, which considers, beyond clinical stability, a corrected gestational age of 34 weeks and weight above 1500 grams, since, departing from this criteria, it is considered that the preterm born baby is capable of presenting coordination among sucking, deglutition and breathing during the oral route feeding ${ }^{7,13}$.

The time of transition for a full feeding via the oral route presented an average of $15,6( \pm 9,7)$ days. This time might be associated to intercurrences which these preterm born infants suffer with the long period of hospital stay, which might be an inherent factor to the difficulty presented in feeding, so as the presence of neurologic immaturity, the inadequate muscular tonus, the weakness in the oral reflexes and the difficulty of keeping the alert state are factors that might be directly linked in the loss of oral skills in preterm newborns².

The adequate moment to begin feeding in preterm born infants has not yet been defined, both in the literature and in practice. In the face of factors that might cause harms in the oral route feeding, several protocols ${ }^{6,9-11,14-16}$ have been applied with a view to measuring the readiness and skill which the preterm newborn infant presents to receive oral feeding in an efficient way as well as to receive, in a safe form, the nutrients needed for their survival. However, randomized studies assessing the risks or the benefits of their utilization for the preterm infant were not found yet.

In this research, it is possible to observe that all the preterm born babies presenting readiness for the beginning of feeding via the oral route in the POFRAS also presented normal oral motor function in the SOMA. Likewise, all the preterm born babies presenting oral motor dysfunction in the SOMA also did not present readiness to start breast feeding. This has thus demonstrated that the results of one evaluation might be complementing another with the intention of certifying that a result presented during a nonnutritive sucking might be confirmed by the result of oral motor skill during the first nutritive sucking with an easily applicable observational tool.

It is possible to observe that some of the preterm newborns did not have readiness to initiate feeding via the oral route in the POFRAS assessment, whereas in the SOMA assessment normal oral motor function was observed in the nutritive sucking. This data suggests that, in the evaluation of the nutritive sucking, without taste stimuli, the infant might present a non satisfactory result; and, besides, by initiating nutritive sucking with milk, the infant may organize himself instinctively and improve the oral pattern for feeding. Yet, these data do not exempt the infants from the necessity of phonoaudiologic monitoring along the evolution of feeding via the oral route.

The data observed in the evaluation of readiness for oral route feeding, both the behavioural ones and those of nonnutritive sucking might not be sufficient for the preterm newborn to be successful in the oral feeding ${ }^{17}$, since the coordination among the sucking, deglutition and breathing functions becomes relevant and can be better assessed during the nutritive sucking ${ }^{18}$. 
In this sample, the time of transition for a full feeding via the oral route showed an average of four days more for the preterm infants presenting lack of readiness in the POFRAS and oral motor dysfunction in the SOMA. Even though this result not being statistically significant, it might be stated that the same presents great clinical relevance, in view that the whole food intake exclusively through oral route in a safe, efficient and independent manner is an important landmark in the development of the preterm newborn, besides being considered one of the criteria utilized for hospital discharge $\mathrm{e}^{19,20}$.

The long time of hospital stay, an inefficient oral stimulation, besides the medical procedures during the hospitalization, might favour the rising of feeding difficulties in the preterm born babies ${ }^{2}$, which very often stunt the mother-baby bond, not benefitting exclusive breast feeding after hospital release.

These findings reveal the importance of the insertion of the phonoaudiologist in the Neonatal Intensive Care Unit team with the intent of inquire whether the preterm born baby presents readiness to initiate feeding via the oral route as well as to check if the same also presents oral skill in the nutritive sucking during the first oral route food supply. With the outcomes obtained during the assessments, the phonoaudiologist might be planning a stimulation program in order to foster the maturation and benefit the maternal lactation in a safe form and without risks of respiratory complications for the preterm born infant.

In this study, it is possible to observe the applicability of SOMA with preterm born infants, even though having been this tool proposed to be applied with more mature newborns and not having been validated for that population. The SOMA might be used as a complementary instrument in the assessment of premature babies, adding information about other evaluations and aiding to determine the difficulty presented by the preterm newborn in the beginning of his feeding via the oral route.

\section{CONCLUSION}

All the preterm newborns presenting readiness to initiate feeding via the oral route manifested normal oral motor function. Those manifesting oral motor dysfunction were the ones who did not present readiness to initiate the first breast feeding.

These outcomes suggest that the SOMA might also be a method for complementing the assessment of the oral motor function in the moment of the release of the oral route of preterm newborns, as well as helping to serve as a guideline in a plan of precocious oral motor sensory stimulation for those presenting any oral motor dysfunction.

The restrictions encountered for this study were: the protocol SOMA not being an instrument validated for application with newborns; and the utilization of the nursing bottle as an assessment instrument. However, the items of this evaluation show some objective aspects to be worked out based on the analysis of the results as well as dysfunctions presented, thus fostering the delineation of a precocious oral motor sensory stimulation directed more to meet the individual needs presented, aiming at providing the preterm born infant with a safe and efficient introduction of feeding via the oral route, besides favouring maternal lactation.

\section{REFERENCES}

1. Scochi CGS, Ferreira FY, Góes FSN, Fujinaga $\mathrm{Cl}$, Ferecini GM, Leite AM. Alimentação láctea e prevalência do aleitamento materno em prematuros durante internação em um hospital amigo da criança de Ribeirão Preto-SP, Brasil. Cienc. Cuid. Saúde. 2008;7(2):145-54.

2. Arvedson J, Clark H, Lazarus C, Schooling T, Frymark T. Evidence-based systematic review: effects of oral motor interventions on feeding and swallowing in preterm infants. Am J Speech Lang Pathol. 2010;19(4):321-40

3. White-Traut R, Pham T, Rankin K, Norr K, Shapiro $\mathrm{N}$, Yoder J. Exploring factors related to oral feeding progression in premature infants. Adv Neonatal Care. 2013;13(4):288-94.

4. Yamamoto RCC, Keske-Soares M, Weinmann ARM. Characteristics of nutritive sucking in the release for oral feeding in preterm newborns of different gestational ages. Rev Soc Bras Fonoaudiol. 2009;14(1):98-105.

5. Prade LS, Bolzan GP, Weinmann ARM. The influence of behavioral state on sucking patterns in preterm infants. Audiol Commun Res. 2014;19(3):230-5.

6. Lau C, Smith EO. A novel approach to assess oral feeding skills of preterm infants. Neonatology. 2011;100(1):64-70.

7. Medeiros AMC, Oliveira ARM, Fernandes AM, Guardachoni GAS, Aquino JPSP, Rubinick ML et al. Characterization of the transition technique from enteral tube feeding to breastfeeding in preterm newborns. J Soc Bras Fonoaudiol. 2011;23(1):57-65. 
8. Macias MER, Meneses GJS. Physiology of nutritive sucking in newborn and infants. Bol Med Hosp Infant Mex. 2011;68(4):296-303.

9. Fujinaga $\mathrm{Cl}$, Scochi CGS, Santos $\mathrm{CB}$, Zamberlan $\mathrm{NE}$, Leite AM. Content validation as a tool for evaluating oral feeding readiness in preterm babies. Rev Bras Saúde Matern Infant. 2008;8(4):391-9.

10. Fujinaga $\mathrm{Cl}$, Moraes $\mathrm{SA}$, Zamberlan-Amorim NE, Castral TC, Silva AA, Scochi CGS. Clinical validation of the Preterm Oral Feeding Readiness Assessment Scale. Rev Lat Am Enfermagem. 2013;21(Spec):140-5.

11. Reilly S, Skuse D, Mathisen B, Wolke D. The objective rating of oral-motor functions during feeding. Dysphagia. 1995;10(3):177-91.

12. Ribeiro FGSM. Protocolo para transição da alimentação para via oral em prematuros. In: Furkim AM, Rodrigues KA. Disfagias nas unidades de terapia intensiva. São Paulo: Roca; 2014. p. 189-99.

13. Wolff $\mathrm{PH}$. The serial organization of sucking in the young infant. Pediatrics. 1968;42(6):94-56.

14. Palmer MM, Crawler K, Blanco IA. Neonatal oral-motor assessment scale: a reliability study. J Perinatol. 1993;13(1):28-35.

15. Thoyre SM, Shaker CS, Pridhan KF. The early feeding skills assessment for preterm infants. Neonat. Network. 2005;24(3):7-16.

16. Neiva FCB, Leone C, Leone CR. Non-nutritive sucking scoring system for pre term new borns. Acta Paediatr. 2008;97(10):1370-5.

17. Ross ES, Browne JV. Feeding outcomes in preterm infants after discharge from the neonatal intensive care unit (NICU): a systematic review. Newborn Infant Nurs Rev. 2013;13(2):87-93.

18. Crowe L, Chang A, Walace K. Instruments for assessing readiness to commence suck feeds in preterm infants: effects on time to establish full oral feeding and duration of hospitalisation. Cochrane Database of Systematic Reviews. 2016;8. Art. No.: CD005586. DOI: 10.1002/14651858.CD005586. pub3

19. American Academy of Pediatrics. Hospital discharge of the high-risk neonate. Pediatrics. 2008;122(5):1119-26.

20. Briere CE, McGrath J, Cong X, Cusson R. State of the Science: A contemporary review of feeding readiness in the preterm infant. J Perinat Neonatal Nurs. 2014;28(1):51-8. 